\title{
Thermal Runaway Avoidance during Burn-in
}

\author{
Arman Vassighi, Oleg Semenov, Manoj Sachdev \\ Electrical and Computer Engineering Dept., University of Waterloo, Waterloo, ON, Canada N2L 3G1 \\ Tel: 519-888-4567-3370; Fax: 519-746-3077; e-mail: avassigh@vlsi.uwaterloo.ca
}

\begin{abstract}
In deep sub-micron technologies, increased standby leakage current in high performance processors results in increased junction temperature. Elevated junction temperature causes further increase on the standby leakage current. The standby leakage current is expected to increase even more under the burn-in environment leading to still higher junction temperature and possibly the thermal runaway. In this paper we investigate the thermal management of high performance processors during burn-in.
\end{abstract}

\section{Introduction}

Stressing during the Burn-in (BI) accelerate the defect mechanisms responsible for early life failures. Thermal and voltage stresses increase the junction temperature resulting in accelerated aging. Elevated junction temperature, in turn, causes leakages to further increase by approximately $3-4 x$, going from nominal to burn-in conditions. In nano-meter regime, this may result into positive feedback leading to the thermal runaway. Figure 1 shows a chip that has gone to thermal runaway. To avoid thermal runaway, it is crucial to understand and predict the junction temperature under the normal and stress conditions. Junction temperature, in turn, is a function of ambient temperature $\left(T_{a}\right)$, junction to ambient thermal resistance $\left(\mathrm{R}_{\mathrm{ja}}\right)$, and static power dissipation.

\section{Junction Temperature Estimation Procedure}

The junction temperature $\left(\mathrm{T}_{\mathrm{j}}\right)$ of an IC is defined as the average temperature of the silicon substrate. The junction temperature or $\mathrm{T}_{\mathrm{j}}$, is defined as [2]:

$T_{j}=T_{a}+P \times R_{j a}$

where $T_{a}$ is the ambient or set point temperature, $P$ is the device total power, and $\mathrm{R}_{\mathrm{ja}}\left(\mathrm{R}_{\mathrm{th}}\right)$ is the junction-to-ambient thermal resistance. The power dissipation can be subdivided into dynamic and leakage components, as:

$$
\begin{aligned}
& P=P_{\text {Dynamic }}+P_{\text {Leakage }} \\
& P_{\text {Leakage }}=V_{D D} \times I_{\text {Leakas }} \\
& P_{\text {Dynamic }}=C \times V_{D D}^{2} \times f_{\text {toggle }}
\end{aligned}
$$

In equation $4, C$ is the total IC switching capacitance and $\mathrm{f}_{\text {toggle }}$ is the frequency that is used for node toggling during burn-in and is expressed as:

$$
f_{\text {toggle }}=\frac{I_{\text {on }}}{C_{\text {gate }} \times V_{D D} \times N}
$$

where $\mathrm{C}_{\text {gate }}$ is the gate capacitance of a single gate and $\mathrm{N}$ is the number of logic stages in the critical path. To evaluate junction temperature, $\mathrm{T}_{\mathrm{j}}$, under different environmental conditions, a program and a methodology has been developed (Fig 2) [3,4].

\section{Simulation Results}

A 32-bit microprocessor in $130 \mathrm{~nm}$ dual $\mathrm{V}_{\mathrm{T}}$ CMOS technology was used to verify the procedure. The parameters of this program were calibrated to the experimental data from the microprocessor. As illustrated in the Figure 3, for air-cooled BI ovens if the $\mathrm{T}_{\mathrm{a}}$ is kept above $10^{\circ} \mathrm{C}$, the $\mathrm{T}_{\mathrm{j}}$ starts rising and does not converge. This rise in temperature will lead the chip to thermal runaway. The same chip in liquid cooled BI oven (solid lines) will tolerate up to $76^{\circ} \mathrm{C}$ of $\mathrm{T}_{\mathrm{a}}$, which results in $110^{\circ} \mathrm{C}$ of $\mathrm{T}_{\mathrm{j}}$. Liquid cooled $\mathrm{BI}$ ovens with $\mathrm{R}_{\mathrm{ja}}$ of $0.5^{\circ} \mathrm{C} / \mathrm{W}$ are able to transfer more heat from the chip than air cooled BI ovens $\mathrm{R}_{\mathrm{ja}}$ of $1.5^{\circ} \mathrm{C} / \mathrm{W}$. Since the total power at $\mathrm{BI}$ condition $\left(\mathrm{T}_{\mathrm{j}}=110^{\circ} \mathrm{C}, \mathrm{V}_{\mathrm{DD}}=1.8 \mathrm{~V}\right)$ for this chip is $66 \mathrm{~W}, 1^{\circ} \mathrm{C} / \mathrm{W}$ reduction in $\mathrm{R}_{\mathrm{ja}}$ will allow us to perform $\mathrm{BI}$ in $66^{\circ} \mathrm{C}$ higher $\mathrm{T}_{\mathrm{a}}$. The results in Figure 3 confirm that the $\mathrm{T}_{\mathrm{a}}$ is increased from $10^{\circ} \mathrm{C}$ to $76^{\circ} \mathrm{C}$ in liquid cooled $\mathrm{BI}$ ovens. It should be noted that since the ambient temperature in air-cooled ovens cannot be less than the room temperature, it is impractical to burnin this microprocessor in air-cooled BI oven as at room temperature ambient, the chip will eventually go to thermal runaway.

Simulations were carried with $10 \%$ reduction in channel length of the transistors in $130 \mathrm{~nm}$ technology to incorporate process variations. This resulted in $\sim 3 \mathrm{x}$ increase in the subthreshold current and consequently $\sim 3 \mathrm{x}$ increase in leakage power. Figure 4 illustrates the simulation results of the chip with $10 \%$ smaller channel length transistors than nominal value in 130 $\mathrm{nm}$ technology. As it can be seen in the Figure 4, the ambient temperature must be reduced from $76^{\circ} \mathrm{C}$ to $30^{\circ} \mathrm{C}$ for liquid cooled BI oven to maintain $\mathrm{T}_{\mathrm{j}}$ at $110^{\circ} \mathrm{C}$. Since it is difficult to maintain the $\mathrm{T}_{\mathrm{a}}$ in $\mathrm{BI}$ ovens around room temperature, it is necessary to reduce the $R_{j a}$ of the $B I$ oven. The next generation $B I$ ovens are expected to have $\mathrm{R}_{\mathrm{ja}}$ of $0.3^{\circ} \mathrm{C} / \mathrm{W}$ using refrigeration as a cooling solution and $\mathrm{R}_{\mathrm{ja}}$ of $0.25^{\circ} \mathrm{C} / \mathrm{W}$ using spray cooling technique as cooling solution, respectively. With $\mathrm{R}_{\mathrm{ja}}$ of $0.25^{\circ} \mathrm{C} / \mathrm{W}$, this processor can be burnt-in in the ambient temperature of $70^{\circ} \mathrm{C}$.

\section{Thermal Runaway}

As mentioned before, temperature and leakage current are strongly correlated and create a positive feedback mechanism. Under BI or normal operating conditions, designers try to control the $T_{j}$ by removing the heat from the chip. As long as the rate of heat removal is greater or equal to the rate of heat generation, the $T_{j}$ remains constant at the designed operating point. When the rate of heat generation becomes greater than the rate of heat removal, $T_{j}$ starts to increase and thermal runaway occurs. Figure 5 shows the transient behavior of $R_{\mathrm{ja}}$. When the chip is powered on, the $\mathrm{R}_{\mathrm{ja}}$ starts to increase and reaches to its steady state condition, which as a typical example is $0.6^{\circ} \mathrm{C} / \mathrm{W}$.

In Figure 6, straight lines are drawn using Equation 1, which can be expressed as:

$$
P_{\text {removed }}=\left(T_{j}-T_{a}\right) / R_{t h}
$$

with ambient temperature of $35^{\circ} \mathrm{C}$. As time increases, the thermal resistance increases from $0^{\circ} \mathrm{C} / \mathrm{W}$ and reaches to steady state value of $0.6^{\circ} \mathrm{C} / \mathrm{W}$. Hence, the straight lines represent transient behavior caused by changing thermal resistance with time. On the other hand, the exponential curve is the generated leakage power or chip leakage power at a given $T_{a}$. The intersection of the straight line (representing the removed power) and the exponential curve (representing the leakage power) represents the steady state operating condition of the system where removed heat is equal to the generated heat. As long as there is an intersection between removed power curve and chip power curve, thermal runaway will not occur. 
In Figure 7, the leakage power of the chip with nominal leakage and the leakage power of the chip with high leakage due to $10 \%$ shorter channel length, versus the $\mathrm{T}_{\mathrm{j}}$ are depicted. It can be seen that the leakage power for the nominal leakage chip has an intersection with removed power curve at $110^{\circ} \mathrm{C}$. The slope of the line is $1 / 0.5^{\circ} \mathrm{C} / \mathrm{W}$ and the $\mathrm{T}_{\mathrm{a}}$ is $80^{\circ} \mathrm{C}$. At higher temperature than $110^{\circ} \mathrm{C}$ the removed power is larger than the chip leakage power and in lower temperature than $110^{\circ} \mathrm{C}$ the leakage power is higher than removed power. This means that from any point in the neighborhood of $110^{\circ} \mathrm{C}$ the temperature will return to $110^{\circ} \mathrm{C}$, which is the design point for BI condition. On the other hand if we look at the curve for the high leakage chip, we see that there is no intersection between this curve and the removed power curve with $\mathrm{R}_{\mathrm{ja}}$ of $0.5^{\circ} \mathrm{C} / \mathrm{W}$. Since at all temperatures the removed power is less than leakage power, for this particular chip, the BI environment will lead the chip to thermal runaway. To overcome the problem the BI environment must be changed. The new environment is shown in the figure with $R_{j a}$ of $0.25^{\circ} \mathrm{C} / \mathrm{W}$ and $T_{a}$ of $70^{\circ} \mathrm{C}$. From this experiment, it can be concluded that for scaled chips with higher leakage power, the setup for BI environment must evolve by either reducing one of the $T_{a}$ and $R_{j a}$ or $a$ combination of both of them. This will shift the removed power curve to the left to intersect the leakage curve of generated power for IC at the designed BI condition.

\section{Conclusion}

In this paper, we investigated the thermal management of high performance chips in the BI environment. An electro thermal analysis tool was developed to analyze thermal runaway possibilities due to self-heating under burn-in environment. It was

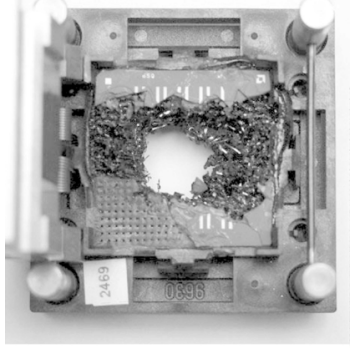

Fig 1. Test socket destroyed by thermal runaway [1].

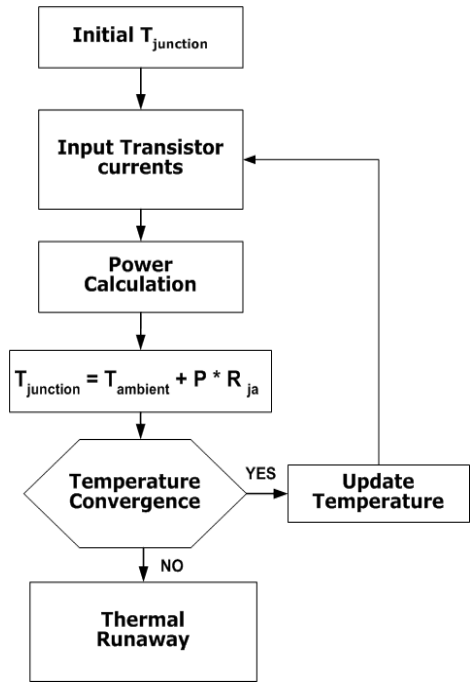

Fig 2. A Procedure for junction temperature estimation [6].

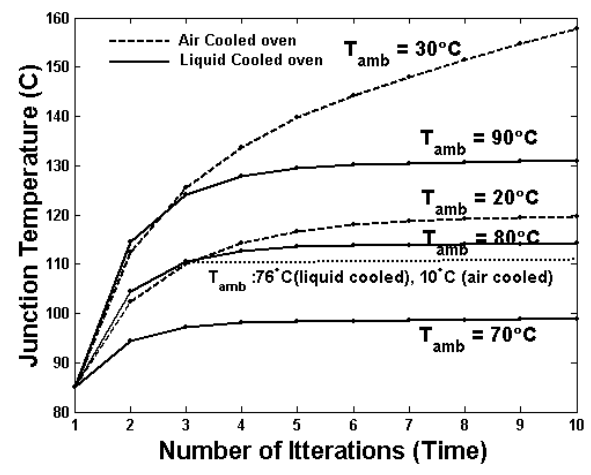

Fig 3. Steady state $\mathrm{Tj}$ for $130 \mathrm{~nm}$ high performance microprocessor at BI condition.

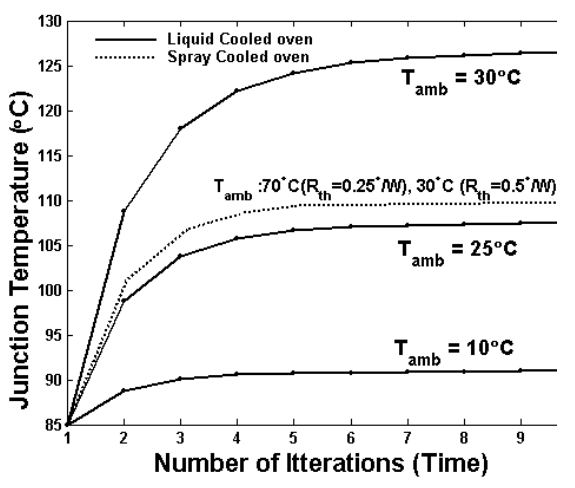

Fig 4. Steady state junction temperature under Burn-in conditions for a $130 \mathrm{~nm}$ Microprocessor with $10 \%$ smaller channel length. concluded that in order to avoid the thermal runaway, the burn-in environment must be set up such that the chip power at any temperature higher than BI temperature be less than removed power so the junction temperature converges to the BI design point temperature.

\section{References:}

[1] Mark Miller (AMD), "Next generation burn-in \& test systems for Athlon microprocessors: hybrid burn-in," Burn-in and Test Socket Workshop, Session 5, 2001.

[2] P. Tadayon, "Thermal challenges during microprocessor testing," Intel Technology Journal, Q3, pp. 1-8, 2000.

[3] K. Kanda, K. Nose, H. Kawaguchi, and T. Sakurai, "Design Impact of Positive Temperature dependence on Drain Current in Sub-1-V CMOS VLSIs", IEEE Journal of Solid-State Circuits, VOL. 36, NO. 10, Oct. 2001

[4] A. Vassighi, O. Semenov, M. Sachdev, and A. Keshavarzi, "Thermal management of high performance microprocessors in burn-in environment," Proc of $18^{\text {th }}$ IEEE International Symposium on Defect and Fault tolerance in VLSI Systems, 2003.

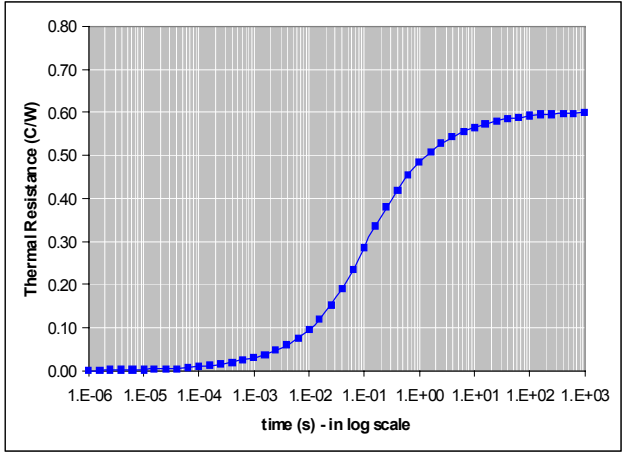

Fig 5. Thermal resistance increases with time and reaches to its steady state value of $0.6^{\circ} \mathrm{C} / \mathrm{W}$.

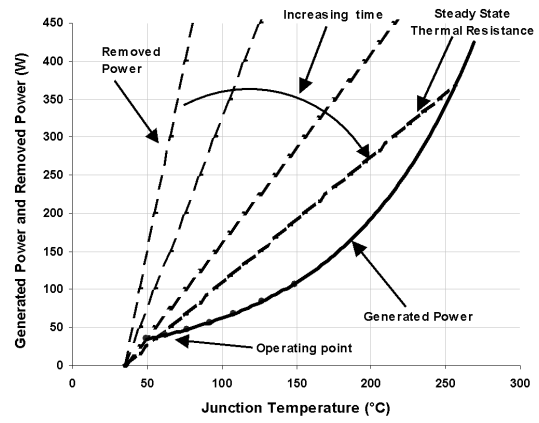

Fig $6.130 \mathrm{~nm}$ microprocessor leakage power (exponential) and removed power (straight lines) for thermal resistance of $0.6^{\circ} \mathrm{C} / \mathrm{W}$.

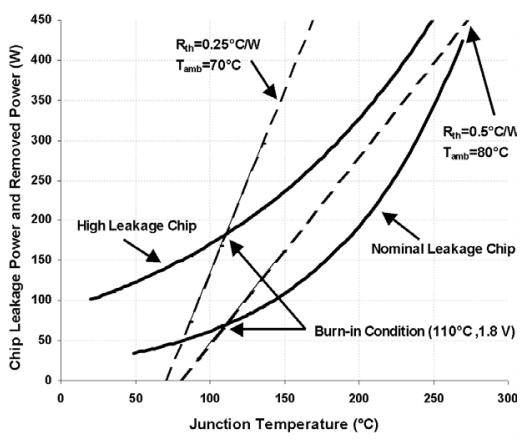

Fig 7. Burn-in setup points for nominal leakage and high leakage chips. 